\title{
A QUICK ASSAY FOR MONITORING RECOMBINANT HIRUDIN DURING CARDIOPULMONARY BYPASS IN PATIENTS WITH HEPARIN-INDUCED THROMBOCYTOPENIA TYPE II: ADAPTATION OF THE ECARIN CLOTTING TIME TO THE ACT II DEVICE
}

Andreas Koster, MD

Matthias Loebe, MD, $\mathrm{PhD}^{\mathrm{c}}$

Roland Hansen, $\mathrm{MD}^{\mathrm{b}}$

Mathias Bauer, MD

Fritz Mertzlufft, MD, $\mathrm{PhD}^{\mathrm{d}}$

Hermann Kuppe, MD, $\mathrm{PhD}^{\mathrm{a}}$

Roland Hetzer, $\mathrm{MD}, \mathrm{PhD}^{\mathrm{c}}$
Background: Recombinant hirudin is increasingly advocated as a promising alternative anticoagulation for patients with heparin-induced thrombocytopenia type II during cardiopulmonary bypass. This requires monitoring of the ecarin clotting time. No commercial ecarin clotting time assay is available for clinical use. We adapted the ecarin clotting time to the easy-to-handle ACT II device.

Methods: Three different concentrations of the ecarin reagent $(20,10,5$ $\mathrm{U} / \mathrm{mL}$ ) were investigated as preliminary studies. Standard calibration curves were constructed for concentrations of recombinant hirudin ranging from 0 to $5 \mu \mathrm{g} / \mathrm{mL}$. In vivo samples were collected from patients with heparininduced thrombocytopenia type II who underwent cardiopulmonary bypass, and the values were compared with the values obtained by the chromogenic method. The final concentration for the assay of $5 \mathrm{IU} / \mathrm{mL}$ ecarin was further assessed in vitro for reproducibility and the influence of variations in hematocrit, platelet count, and procoagulants.

Results: All three concentrations of ecarin revealed linearity to $5 \mu \mathrm{g} / \mathrm{mL}$ concentrations of recombinant hirudin. The ecarin concentration of $5 \mathrm{U} / \mathrm{mL}$ revealed the best correlation $(0.87)$ to the laboratory method, was reproducible over the whole recombinant hirudin range, and was not influenced by the variations in the in vitro setup.

Conclusions: The ACT II/ecarin clotting time with an ecarin concentration of $5 \mathrm{U} / \mathrm{mL}$ is a simple and reliable assay for monitoring recombinant hirudin during cardiopulmonary bypass. Use of this assay allows a wider use of recombinant hirudin in patients with heparin-induced thrombocytopenia type II during bypass and thereby may contribute to the safer management of these patients. (J Thorac Cardiovasc Surg 2000;119:1278-83)
$\mathrm{R}$ ecombinant hirudin (r-hirudin) is a promising new alternative for anticoagulation in patients with heparin-induced thrombocytopenia type II (HIT II) dur-

From the Department of Anesthesiology, ${ }^{a}$ Deutsches Herzzentrum Berlin; Department of Laboratory Medicine and Pathobio-

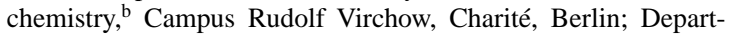
ment of Cardiothoracic and Vascular Surgery, ${ }^{c}$ Deutsches Herzzentrum Berlin; and Department of Anesthesiology and Intensive Care Medicine, ${ }^{\mathrm{d}}$ University of Homburg-Saar, Germany.

Received for publication July 15, 1999; revisions requested Oct 28, 1999; revisions received Jan 13, 2000; accepted for publication Feb 1, 2000.

Address for reprints: Andreas Koster, MD, Deutsches Herzzentrum Berlin, Augustenburgerplatz 1, 13353 Berlin, Germany (E-mail: koster@dhzb.de).

Copyright (C) 2000 by The American Association for Thoracic Surgery

0022-5223/2000\$12.00+ $0 \quad \mathbf{1 2 / 1 / 1 0 6 0 8 8}$

doi: $10.1067 / \mathrm{mtc} .2000 .106088$ ing cardiopulmonary bypass (CPB). ${ }^{1,2}$ When compared with other options, the effect of r-hirudin is achieved immediately, the renal elimination is fast, and, because of its protein structure, r-hirudin does not cross-react with heparin-induced antibodies as described in approximately $10 \%$ of patients given the heparinoid danaparoid sodium (Orgaran). ${ }^{3}$ The use of r-hirudin during CPB necessitates close monitoring of its concentration via measurement of the ecarin clotting time (ECT). However, the only available ready-to-use pointof-care assay for this test, the ECT card for the TAS analyzer (Cardiovascular Diagnostics Inc, Raleigh, NC) is only available for investigational use, although it has been used during emergency $\mathrm{CPB}{ }^{1}$ The originally described method ${ }^{4,5}$ has drawbacks, because both experience in the handling of the device and close attention during the performance of the test are necessary. Moreover, precise measurement of the ECT depends on 
sufficient (60\%) prothrombin and fibrinogen levels, ${ }^{5,6}$ particularly for monitoring higher concentrations $(>2$ $\mu \mathrm{g} / \mathrm{mL}$ ) of r-hirudin. During prolonged perfusions, however, apart from the hemodilution on the CPB system, procoagulants and platelets are progressively consumed on the foreign surfaces.

We adapted the original method of ECT measurement to the commonly used ACT II device (Medtronic, Inc, Minneapolis, Minn) and tried to make it more independent of the patients' procoagulant status.

\section{Patients and methods}

The ACT II/ECT coagulation measurement is based on a mechanical method of clot detection. The reagent is pipetted into the bottom of the cartridges where originally the kaolin for activated clotting time measurement is placed. After insertion of the plastic flags, the blood sample is placed into the blood chamber. After an automated period of incubation, the flags are moved in the device. Clot formation is confirmed by optical detection of inhibition of the flag movement. According to a standard calibration curve, the measured time for clot formation is related to a defined anticoagulant concentration. Tests are performed in duplicate in double cartridges.

Preparation of the cartridges and ecarin concentrations. HEPES buffer was prepared as follows: $50 \mathrm{~mL}$ of $\mathrm{CaCl}_{2}$ in a concentration of $0.1 \mathrm{~mol} / \mathrm{L}+40 \mathrm{~mL}$ of HEPES buffer in a concentration of $1 \mathrm{~mol} / \mathrm{L}+4 \mathrm{~mL}$ of $5 \%$ bovine serum albumin $+106 \mathrm{~mL} \mathrm{H}_{2} \mathrm{O}$ was titrated to a $\mathrm{pH}$ of 7.0. Then, $50 \mathrm{U}$ of lyophilized ecarin (Loxo $\mathrm{GmbH}$, Heidelberg, Germany) was dissolved in $2.5 \mathrm{~mL}$ of the solution of HEPES buffer. This resulted in an ecarin concentration of $20 \mathrm{U}$ in the stock solution. Concentrations of $10 \mathrm{U}$ and $5 \mathrm{U}$ were achieved by further dilution of this solution.

The reaction chamber of the blank cartridges (Medtronic, Inc) was filled with $75 \mu \mathrm{L}$ of the ecarin reagent and the flags were inserted. Then $75 \mu \mathrm{L}$ of standard human plasma (Behringwerke, Marburg, Germany) and $75 \mu \mathrm{L}$ of citrated whole blood were placed into the blood chamber and the test was started.

In vitro setup. After informed consent, citrated whole blood samples were collected from 5 healthy volunteers for the in vitro setup ( 3 men and 2 women, aged $35-46$ years). The samples were spiked with the following concentrations of r-hirudin (Refludan; Hoechst, Frankfurt, Germany), 0, 1, $2,3,4$, and $5 \mu \mathrm{g} / \mathrm{mL}$, to establish a standard calibration curve.

After the final ecarin concentration was determined, in a second part of the in vitro setup, the within-assay variance of the final preparation of $5 \mathrm{U} / \mathrm{mL}$ ecarin reagent was examined by $5 \times$ duplicate measurements of the same sample for $\mathrm{r}$ hirudin concentrations of $1 \mu \mathrm{g} / \mathrm{mL}$ and $5 \mu \mathrm{g} / \mathrm{mL}$.

Furthermore, the stability of the prepared and stored cuvettes was investigated. Therefore, the ecarin was placed in the cartridge, and the flag was inserted and overlaid with the plasma. Afterward, the samples were stored at $-80^{\circ} \mathrm{C}$. The

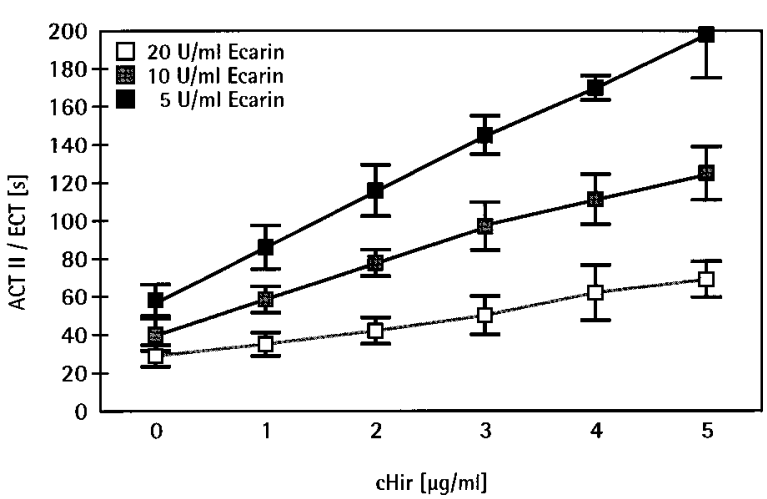

Fig 1. Calibration curve for r-hirudin and ACT II/ECT using three different concentrations of ecarin reagent. ECT, Ecarin clotting time; $c H i r$, concentration of hirudin.

cartridges were defrosted after a period of 1, 2, 4, and 12 weeks. Measurements were performed in citrated whole blood samples spiked with 1 and $5 \mu \mathrm{g} / \mathrm{mL}$ concentrations of r-hirudin and compared with the results of freshly prepared ecarin cartridges. Each measurement was performed in $5 \times$ duplicate measurements.

In addition, the influence of variations in hematocrit value, platelet count, and plasmatic coagulation factors on the test results were assessed. Therefore, the samples were prepared according to the following:

- Three ranges of hematocrit $(20 \%, 30 \%$, and $60 \%)$ obtained by centrifugation and adjustment of the plasma fraction

- Three concentrations of platelets $\left(100 \cdot 10^{3} / \mathrm{mL}, 50\right.$. $10^{3} / \mathrm{mL}$, and $30 \cdot 10^{3} / \mathrm{mL}$ ) obtained by centrifugation of platelet-rich plasma and adjusted to the desired value with platelet-poor plasma

- Three different concentrations of procoagulants $(50 \%$, $30 \%$, and $10 \%$ of the initial value) obtained by substitution of platelet-poor plasma with adequate volumes of a $5 \%$ solution of albumin

In vivo setup. The in vivo investigation was performed with the ecarin reagent concentrations of 5 and $10 \mathrm{U} / \mathrm{mL}$. After approval by the local ethics committee and informed consent, 5 patients with HIT II who underwent cardiac surgery (coronary artery bypass grafting, $\mathrm{n}=2$; aortic valve replacement, $\mathrm{n}=2$; aortic valve replacement + bypass grafting, $\mathrm{n}=1$ ) with $\mathrm{r}$-hirudin as the anticoagulant were included in the investigation.

The r-hirudin regimen for anticoagulation of CPB consisted of a bolus of $0.25 \mathrm{mg} / \mathrm{kg}$ of body weight for the patient and 0.20 $\mathrm{mg} / \mathrm{kg}$ of body weight in the priming solution. When a hirudin concentration of 3.5 to $4.0 \mu \mathrm{g} / \mathrm{mL}$ was achieved, CPB was initiated. This concentration was maintained by an infusion of $r$ hirudin that was adjusted to the actual measured level. The rhirudin level was monitored with the TAS analyzer. In all patients, aprotinin, the kallikrein inhibitor and antifibrinolytic 

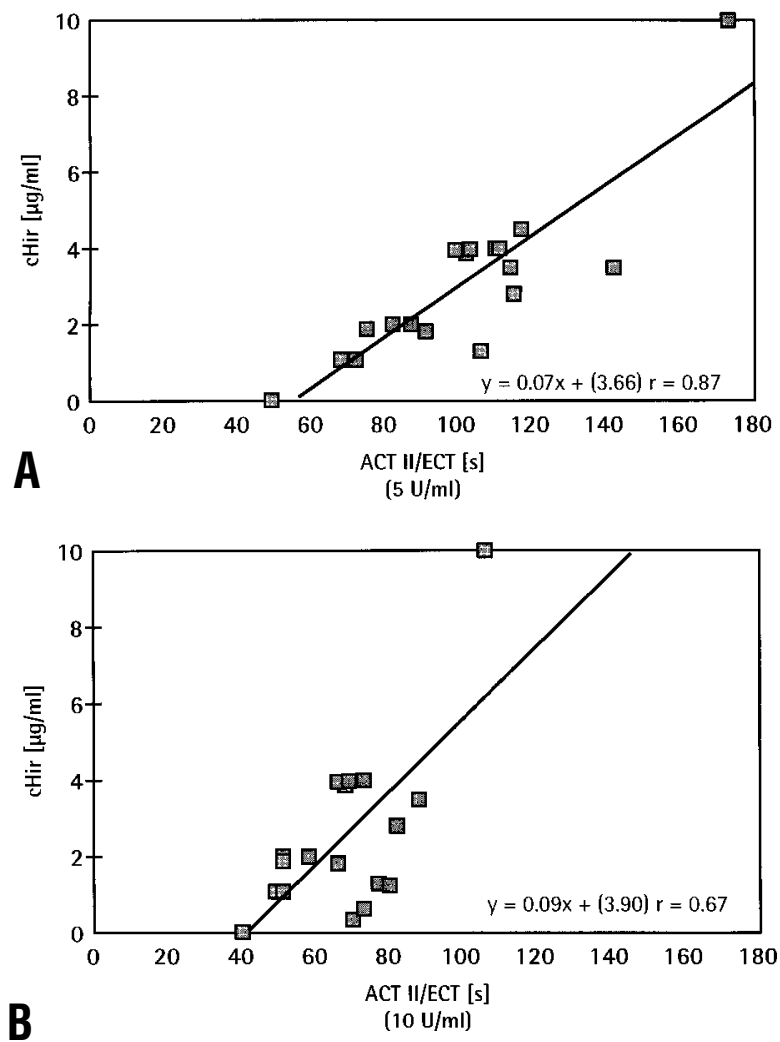

Fig 2. Correlation of the ACT II/ECT to the plasmatic chromogenic assay. ECT, Ecarin clotting time; $c H i r$, concentration of hirudin.

agent, was used according to a high-dose regimen with a bolus of $2 \times 10^{6} \mathrm{kIU}$ for the patient and in the priming solution and a constant infusion of 500,000 kIU/h during CPB.

Citrated whole blood samples were taken every 20 minutes during CPB and for 2 hours after CPB.

Chromogenic reference test. The chromogenic test was performed in plasma. The plasma sample was incubated with tris (hydroxymethyl) aminomethane hexadimethrine bromide (Polybrene) buffer, S-2238 substrate (Chromogenix, Essen, Germany), and thrombin reagent (Boehringer, Mannheim, Germany) and measured with a COBAS MIRA analyzer (Behringwerke, Marburg, Germany) at an extinction value of $405 \mathrm{~nm}$.

Statistical analysis. Statistical analysis of the influence of variations of the hematocrit value, platelet count, and plasmatic coagulation factors was performed by means of analysis of variance with the Scheffé test. A $P$ value of $<0.01$ was defined as statistically significant. The TAS/ECT and laboratory chromogenic results were analyzed by the Pearson correlation coefficient test.

\section{Results}

Standard calibration curves. The standard calibration curves of all three ecarin reagents revealed linearity to r-hirudin concentrations from 0 to $5 \mu \mathrm{g} / \mathrm{mL}$. However, the range between the 0 and $5 \mu \mathrm{g} / \mathrm{mL}$ r-hirudin of $40 \mathrm{sec}-$ onds in the ecarin concentration of $20 \mathrm{U} / \mathrm{mL}$ was considered to be too narrow for precise differentiation of the $\mathrm{r}$ hirudin concentrations. In contrast, with the use of the 10 and $5 \mathrm{U} / \mathrm{mL}$ ecarin reagents, the test range was spread over ranges of 80 and 140 seconds, respectively (Fig 1). Therefore, only these reagent concentrations were used for the in vivo evaluation.

In vivo evaluation. $\mathrm{CPB}$ ranged from 55 to 125 minutes with a mean of $75 \pm 23$ minutes. The initial r-hirudin requirement ranged from 0.25 to 0.45 $\mathrm{mg} / \mathrm{kg}$ of body weight with a mean of $0.28 \pm 0.6$ $\mathrm{mg} / \mathrm{kg}$ of body weight. The total $\mathrm{r}$-hirudin requirement ranged from 0.65 to $1.50 \mathrm{mg} / \mathrm{kg}$ of body weight with a mean of $0.78 \pm 0.18 \mathrm{mg} / \mathrm{kg}$.

The hematocrit values ranged from $22 \%$ to $48 \%$ (mean 27\% $\pm 8.7 \%$ ).

No clot formation was found in the heart-lung machine after termination of CPB. In the first 24 hours, the postoperative blood loss of the patients ranged from 150 to $550 \mathrm{~mL}$ with a mean of $325 \pm 75 \mathrm{~mL}$.

The chromogenically measured r-hirudin plasma concentration ranged from 0.02 to $10 \mu \mathrm{g} / \mathrm{mL}$. The correlation of the $5 \mathrm{U} / \mathrm{mL}$ ecarin reagent to the chromogenic method was 0.87 (Fig 2, A), and the correlation of the $10 \mathrm{U} / \mathrm{mL}$ ecarin reagent was 0.67 (Fig 2, B).

In vitro evaluation of the final assay. The ecarin concentration of $5 \mathrm{U} / \mathrm{mL}$ was evaluated as the final concentration of the test. The within-assay variation coefficient measured for $r$-hirudin concentrations of 1 and $5 \mu \mathrm{g} / \mathrm{mL}$ was less than $5 \%$ (Table I). The difference between measurements obtained from the cuvettes stored for 12 weeks at $-80^{\circ} \mathrm{C}$ and the freshly prepared cuvettes was below 5\% (Table II). The test was not significantly influenced by variations of the hematocrit value from $60 \%$ to $20 \%$ (Fig 3, A). Moreover, the test results were not influenced by a reduction of the platelet count to $30,000 / \mathrm{mL}$ (Fig 3, $B)$ and a reduction of the plasmatic coagulation factors to $10 \%$ (Fig 3, C).

\section{Discussion}

Currently used whole blood point-of-care monitoring assays, such as the activated clotting time or the activated partial thromboplastin time, are not reliable for monitoring anticoagulation with r-hirudin during CPB. ${ }^{4}$ Therefore, the use of r-hirudin for anticoagulation of CPB in patients with HIT II has been largely restricted because of the lack of a reliable monitoring technique in the operating room. ACT II/ECT is easy to measure and enables hirudin levels to be controlled to maintain sufficient anticoagulation during CPB. 
Table I. Within-assay variability of the final ACT II/ECT assay

\begin{tabular}{|c|c|c|c|c|c|c|c|c|c|c|c|c|c|}
\hline$c H i r(\mu g / m L)$ & & & & & $E C T$ & & & & & & Mean & $S D$ & $V C$ \\
\hline 1 & 85 & 87 & 85 & 88 & 87 & 90 & 86 & 86 & 85 & 88 & 86.7 & 1.64 & 1.90 \\
\hline 5 & 206 & 212 & 205 & 212 & 196 & 204 & 204 & 212 & 210 & 208 & 206.8 & 4.80 & 0.23 \\
\hline
\end{tabular}

cHir, Concentration of hirudin; $S D$, standard deviation; $V C$, variation coefficient.

The ACT II device is produced for measurement of the kaolin activated clotting time with prepared cartridges. This global coagulation assay is mainly used for monitoring anticoagulation with unfractionated heparins during CPB or angioplasty in the heart catheterization laboratory. However, with the use of blank cartridges and the addition of the originally plasma-based Heptest reagent (Boehringer), an anti-Xa activity test is created for monitoring the levels of low molecular weight heparins as well as unfractionated heparins in citrated whole blood. ${ }^{7}$ The addition of ecarin into the reaction chamber of the cartridge provides an easy-to-perform ECT assay for monitoring direct thrombin inhibitors such as r-hirudin.

The ACT II device appears to be preferable to other options for adapting other more specific coagulation tests, as tests are performed in double cartridges and the low-range cartridge needs a volume of only $200 \mu \mathrm{L}$ in comparison with $2 \mathrm{~mL}$ needed in other devices. Moreover, the automated period is integrated. As the reagents are major contributors to the cost of the assay, reducing the volumes of reagents needed effectively reduces the costs of the tests.

The ECT assay is based on the principle of ecarininduced conversion of prothrombin to meizothrombin. Meizothrombin inhibits hirudin by the formation of a stable 1:1 complex. After the neutralization of $r$ hirudin, coagulation is initiated (in a slower reaction when compared with thrombin) by meizothrombin itself via the conversion of fibrinogen to fibrin. Therefore, a coagulation time can be related to a determined hirudin level. However, it is important to provide high fibrinogen and prothrombin levels for precise measurement of particularly higher $(>2$ $\mu \mathrm{g} / \mathrm{mL}$ ) r-hirudin levels. ${ }^{5,6}$ Because procoagulants are diluted and depleted by contact activation on the surfaces of the extracorporeal system during $\mathrm{CPB}$, the use of the ACT II/ECT enables sufficient fibrinogen and prothrombin levels to be ensured by 1:1 dilution of the blood sample with standard human plasma. However, because of this procedure, the r-hirudin concentration in the sample is halved. Therefore, the use of the original $20 \mathrm{U} / \mathrm{mL}$ ecarin solution led to a too narrow running time to ascertain the r-hirudin levels
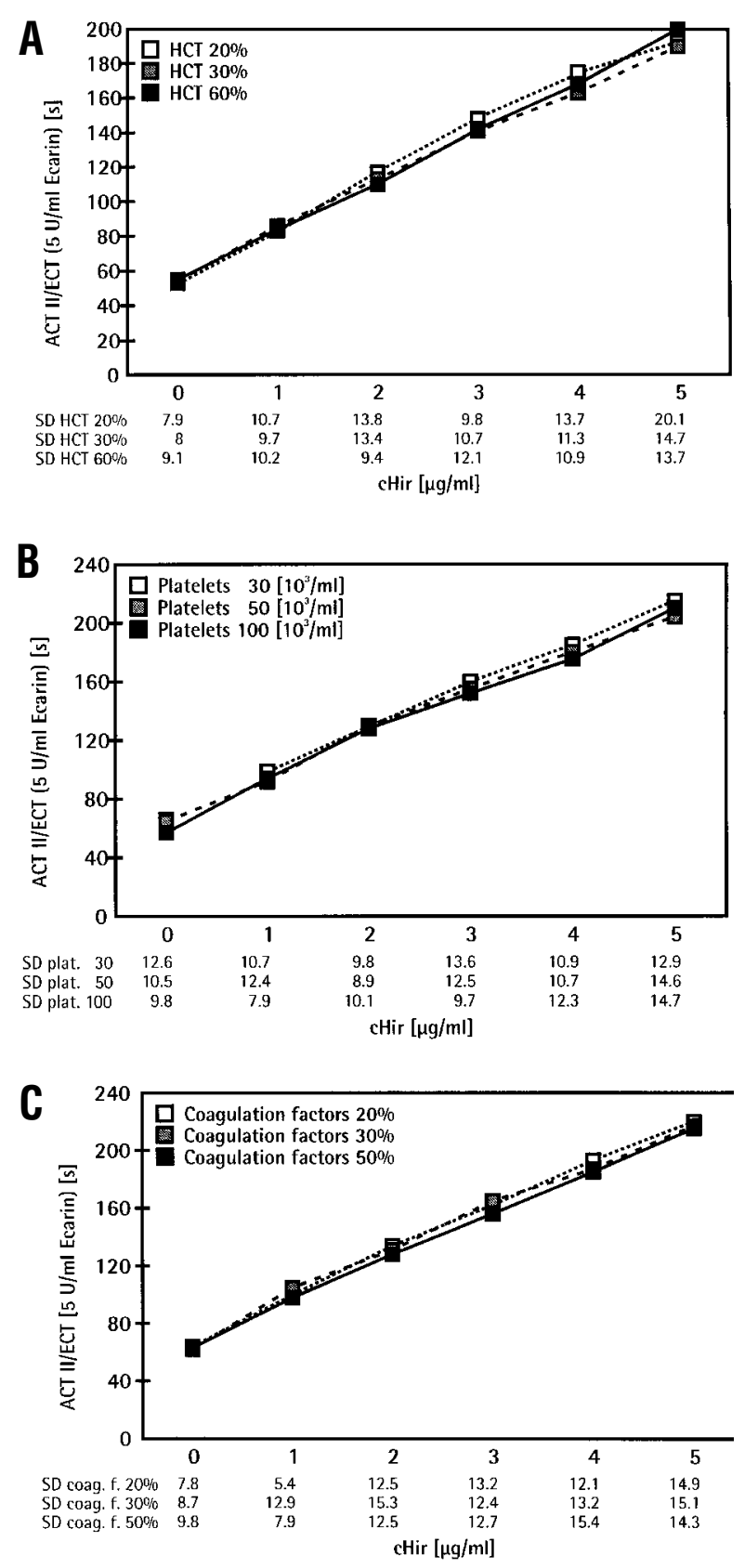

Fig 3. Influence of variations in the hematocrit value, platelet count, and coagulation factors on ACT II/ECT assay. ECT, Ecarin clotting time; $\mathrm{cHir}$, concentration of hirudin; $\mathrm{HCT}$, hematocrit. 
Table II. Influence of storage time at $-80^{\circ} \mathrm{C}$ on the ACT II/ECT values

\begin{tabular}{|c|c|c|c|c|c|c|c|c|c|}
\hline \multirow[b]{3}{*}{$c H i r(\mu g / m L)$} & & \multicolumn{8}{|c|}{ Duration of storage (wk) } \\
\hline & & \multicolumn{2}{|c|}{1} & \multicolumn{2}{|c|}{2} & \multicolumn{2}{|c|}{4} & \multicolumn{2}{|c|}{12} \\
\hline & & $M V$ & $S D$ & $M V$ & $S D$ & $M V$ & $S D$ & $M V$ & $S D$ \\
\hline Stored & 1 & 86 & \pm 0.2 & 85 & \pm 0.1 & 84 & \pm 0.15 & 86 & \pm 0.1 \\
\hline Nonstored & 1 & 85 & \pm 0.3 & 85 & \pm 0.2 & 85 & \pm 0.1 & 87 & \pm 0.2 \\
\hline Stored & 5 & 207 & \pm 4.8 & 199 & \pm 4.2 & 208 & \pm 5.7 & 205 & \pm 4.9 \\
\hline Nonstored & 5 & 198 & \pm 5.2 & 203 & \pm 5.1 & 201 & \pm 4.9 & 198 & \pm 5.1 \\
\hline Variation (\%) & & 1.04 & & 0.98 & & & 1.03 & & 1.03 \\
\hline
\end{tabular}

$E C T$, Ecarin clotting time; $M V$, mean value of 5 measurements in duplicate; $S D$, standard deviation; Variation, stored/nonstored $\times 100$.

between 0 and $5 \mu \mathrm{g} / \mathrm{mL}$ (approximately 30 seconds, Fig 1). Therefore, the ecarin concentration was reduced to prolong the coagulation time of the assay. The $5 \mathrm{U} / \mathrm{mL}$ concentration of ecarin demonstrated linearity for a r-hirudin concentration of up to $5 \mu \mathrm{g} / \mathrm{mL}$, which is above the recommended concentration for anticoagulation of $\mathrm{CPB}^{4}$ and demonstrated an excellent correlation to the non-hematocrit corrected values of the plasmatic chromogenic test $(r=0.87)$. However, although the correlation of the ACT II/ECT was excellent (0.87), the scattering needs an explanation (Fig 2, A). The chromogenic test was performed in plasma and not corrected for the actual hematocrit value. Therefore, the results were influenced by the large variation in the hematocrit value (22\%-48\%), which reduced the agreement between the two assays. The test range of 140 seconds between the 0 and 5 $\mu \mathrm{g} / \mathrm{mL}$ values (200 seconds total) was evaluated as optimal in terms of quick results and better differentiation of the r-hirudin concentrations. With this concentration, the assay revealed reproducible and reliable measurements of the r-hirudin level, even in cases of marked hemodilution, decrease in platelet count, and loss of coagulation factors, which particularly occur during prolonged CPB.

Because the ecarin solution remains stable at $-80^{\circ} \mathrm{C}$, as has been demonstrated previously, the test cartridges can be prepared and stored. ${ }^{4}$ Moreover, the standard human plasma can be overlaid after insertion of the flags before the cartridges are frozen. This ensures that the cartridges can be stored for at least 3 months and are ready to use if needed (Table II). As the incubation period is automated in contrast to the original method, only one working step is necessary in the operating room, and it can be easily performed by the anesthetist or perfusionist during the operation.

However, with regard to the inter-individual variations in the r-hirudin response, as seen in the calibration curves (Fig 1), the establishment of an individual calibration curve before application of r-hirudin is recommended for precise measurement. This can be quickly ( $<15$ minutes) achieved by the use of deep frozen previously pipetted solutions of r-hirudin.

However, if CPB has to be established immediately, on an emergency basis, a value of 180 to 200 seconds appears to be appropriate to initiate $\mathrm{CPB}$. According to the calibration curve, this value represents a concentration of approximately $4 \mu \mathrm{g} / \mathrm{mL}$ of r-hirudin. Therefore, after the initiation of $\mathrm{CPB}$, the individual calibration curve can be quickly constructed by use of a previously obtained whole blood sample and the concentration adjusted to the individual demands by up- or down-regulation of the continuous r-hirudin infusion.

We conclude that the ACT II-modified ECT is a reliable, easy-to-perform, and inexpensive point-of-care assay for monitoring r-hirudin during CPB. Thus, it may contribute to a wider use of r-hirudin and to the safer management, particularly during CPB, of patients with HIT II. However, further investigations with larger numbers of patients are necessary for a final clinical evaluation of the assay.

We thank Miss Annette Gaussmann for the illustrations and Miss Tonie Derwent for her professional editorial assistance.

\section{REFERENCES}

1. Koster A, Kuppe H, Hetzer R, Sodian R, Crystal GJ, Mertzlufft F. Emergent cardiopulmonary bypass in five patients with heparin-induced thrombocytopenia type II employing recombinant hirudin. Anesthesiology 1998;89:777-80.

2. Greinacher A, Völpel H, Jansens U, Hach-Wunderle V, KempkesMathes B, Eichler P, et al. Recombinant hirudin (Lephirudin) provides safe and effective anticoagulation in patients with heparin-induced thrombocytopenia: a prospective study. Circulation 1999;99:73-80.

3. Laposata M, Green D, van Cott E, Barrowcliffe T, Goodnight SC, Sosolik RC. College of American Pathologists Conference XXXI 
on laboratory monitoring of anticoagulant therapy: the clinical use and laboratory monitoring of low-molecular-weight heparin, danaparoid, hirudin and related compounds, and argatroban. Arch Pathol Lab Med 1998;122:799-807.

4. Pötzsch B, Madlener K, Seelig C, Riess CF, Greinacher A, Muller-Berghaus G. Monitoring of r-hirudin anticoagulation during cardiopulmonary bypass-assessment of the whole blood ecarin clotting time. Thromb Haemost 1997;77:920-5.
5. Poetzsch B, Hund S, Madlener K, Unkrig C, Müller-Berghaus G. Monitoring of recombinant 6 hirudin: assessment of the plasma based ecarin clotting time. Thromb Res 1997;89:373-83.

6. Nowack G, Bucha E. Quantitative determination of hirudin in blood and body fluids. Semin Thromb Hemost 1996;22:197—2.

7. Hansen R, Koster A, Mertzlufft F. A new assay for point of care monitoring of heparin and heparinoid anti-Xa activity [abstract]. Anesth Analg 1999;88:SCA 4.

Access to The Journal of Thoracic and Cardiovascular Surgery Online is now reserved for print subscribers!

Full-text access to The Journal of Thoracic and Cardiovascular Surgery Online is now available for all print subscribers. To activate your individual online subscription, please visit The Journal of Thoracic and Cardiovascular Surgery Online, point your browser to http://www.mosby.com/jtcvs, follow the prompts to activate your online access, and follow the instructions. To activate your account, you will need your subscriber account number, which you can find on your mailing label (note: the number of digits in your subscriber account number varies from 6 to 10). See the example below in which the subscriber account number has been circled:

Sample mailing label

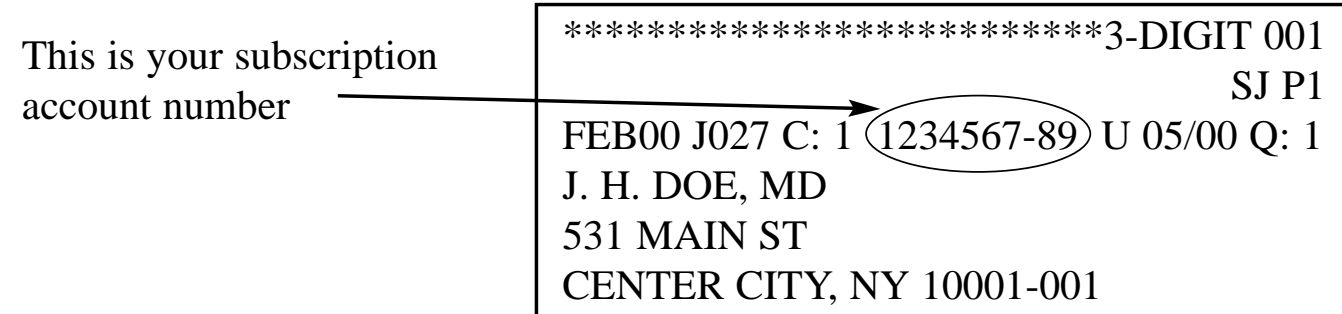

Personal subscriptions to The Journal of Thoracic and Cardiovascular Surgery Online are for individual use only and may not be transferred. Use of The Journal of Thoracic and Cardiovascular Surgery Online is subject to agreement to the terms and conditions as indicated online. 